\title{
Computer simulation of water effluent propagation in the reservoirs systems
}

\author{
Sevara Kurakbayeva ${ }^{1}$, Zhanat Umarova ${ }^{1}$, Aizhan Kalbayeva ${ }^{1}$, Dzhumagali Kurakbayev ${ }^{2}$, \\ Sabira Akhmetova ${ }^{3}$, Akhmetbek Musabekov ${ }^{4}$ \\ ${ }^{1}$ Department of Informaition systems and modeling, Information technologies and Energetics Higher School, \\ M. Auezov South Kazakhstan University, Tauke Khan Avenue 5, Shymkent, Kazakhstan \\ ${ }^{2}$ Department of Computer science, Natural-Scientific-Pedagogical Higher School, M. Auezov South Kazakhstan University, \\ Tauke Khan Avenue 5, Shymkent, Kazakhstan \\ ${ }^{3}$ Department of Computing systems and software, Information technologies and Energetics Higher School, \\ M. Auezov South Kazakhstan University, Tauke Khan Avenue 5, Shymkent, Kazakhstan \\ ${ }^{4}$ Department of Automation, telecommunications and control, Information technologies and Energetics Higher School, \\ M. Auezov South Kazakhstan University, Tauke Khan Avenue 5, Shymkent, Kazakhstan
}

\begin{tabular}{l} 
Article Info \\
\hline Article history: \\
Received Jul 26, 2021 \\
Revised Jan 11, 2022 \\
Accepted Jan 24, 2022 \\
\hline
\end{tabular}

Keywords:

Computer modelling Connected reservoirs Mathematical model Numerical experiment Pollutant propagation Relaxation time Software system

\section{Corresponding Author:}

Zhanat Umarova

Department of Informaition Systems and Modeling, Information Technologies and Energetics Higher School M. Auezov South Kazakhstan University

Tauke Khan Avenue 5, Shymkent, Kazakhstan

Email: zhanat.umarova@auezov.edu.kz

\begin{abstract}
The task of the research was to build and analyze a model of the dynamics of pollution of a flowing reservoir and systems of communicating reservoirs with and without taking into account water filtration in the soil as a result of external sources (effluents from industrial enterprises). This work was aimed at studying the change in temporal dynamics, taking into account the concentration of impurities in the volumes of three reservoirs during the periods of discharge and completion, lasting 30 days. Numerical experiments were carried out for various flow rates and compositions of filtration coefficients to study the relaxation times of pollution in the system of reservoirs. Also, software was developed that analyzes the change in the concentration of impurities in the system of reservoirs. As a result, it was found that the pollution pattern is more dependent on the topology of the watercourse network.
\end{abstract}

This is an open access article under the CC BY-SA license.

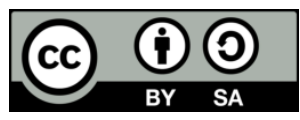

\section{INTRODUCTION}

Many scientific research papers consider mathematical modeling of water systems [1]-[5]. The analysis of the considered literary sources showed the possibility of conditionally dividing the main mathematical models of water systems into 2 classes: those used in forecasting and those used for monitoring. Mathematical models of water systems have a number of features. First of all, this is due to the very object being modeled-water. Models describing the water environment are multi-criteria since they provide both economic and environmental needs of society. When setting such tasks, there is a need for an integrated and versatile approach to the study of the problem [6], [7]. Another feature of the water system is its dynamism, i.e., any process in the environment should be considered in time. Research papers [8]-[10] show that mathematical models used to study the water environment are complex and diverse in their structure. To build models of this type, it is very important to correctly formulate the problem statement and generalize the available initial data, then choose the optimal solution method. 
Analysis of literary sources shows that, despite a large number of studies, the known models describing the dynamic distribution of pollutants in the water system are complex and limited. Theoretical concepts of impurity spreading ways in the water environment and distribution in the system of water reservoirs require further development and improvement [11]-[13]. Today, the study of the degree of pollution in reservoir systems has received great practical interest. The results of such studies are widely used to solve various problems in ecology [14]-[18]. This approach involves the use of simplified samples for the analysis of dynamic pollution of running water reservoirs in neighboring systems of reservoirs, considering options with and without taking into account water filtration in the soil under the influence of external sources (discharges from industrial enterprises). The next step for the development of the model is the application of an analysis of the change in the concentration of impurities in the system of co-correlating reservoirs under consideration, taking into account the diffusion process of impurities in water bodies and soil filtration, i.e., in the dynamic model, typical periods of impurity propagation within each reservoir should be provided.

\section{RESEARCH METHOD}

Industrial emissions can be distributed in a system of interconnected storage facilities, the result of which for the most part is a rather complex pollution situation [19]-[21]. This article examines a system consisting of three reservoirs. In the coastal zone of one of the reservoirs, there izs a source of pollution with a given intensity Figure 1.

At the beginning, the condition of total expense balance by flows in the system was offered. This condition means, in fact, neglecting the water filtration system in the soil. Further, in order for the development of the model to be directed to the dynamic analysis of the concentration of additives in the system of communicating reservoirs, taking into account diffuse impurities in reservoirs and filtration in the soil, it was necessary to introduce the characteristic times of impurity propagation in the volumes of each reservoir in the dynamic model [21]. Figure 2 shows the flow diagram in the system of three communicating reservoirs, taking into account filtration.

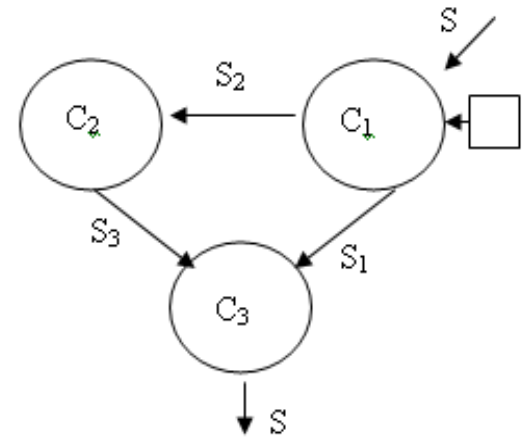

Figure 1. The flows scheme in the system of three co-correlating reservoirs without taking into account water filtration in the soil

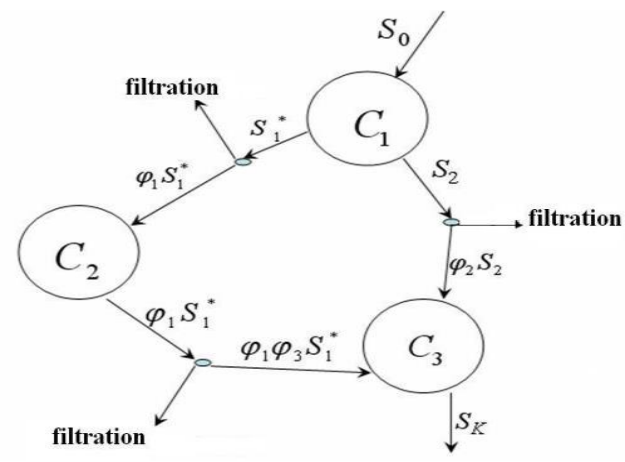

Figure 2. Flows scheme of the three connected water reservoirs system with the filtration consideration

The article highlights the main points that are associated with the dependences of the following characteristics: on the relaxation time in each of the reservoirs, depending on the duration of the discharge, as well as the coefficients of water filtration in the soil [21]. Therefore, the main goal of our research was to determine the dependence between the concentrations of impurities in each of the reservoirs on the intensity of filtration in the channels connecting these reservoirs in a given period of time [22].

\subsection{A case of no filtration in the soil}

Let's to write down the system of differential equations for calculating the balance of pollution of the reservoir with stable impurities, provided that the condition of filtration in the soil can be neglected,

$$
\left\{\begin{array}{c}
V_{1} \frac{d c_{1}}{d t}=I(t)-s * c_{1} \\
V_{2} \frac{d c_{2}}{d t}=\left(s-s_{1}\right) * c_{1}-\left(s-s_{1}\right) * c_{2} \\
V_{3} \frac{d c_{3}}{d t}=s_{1} * c_{1}+\left(s-s_{1}\right) * c_{2}-s * c_{3}
\end{array}\right.
$$


where $c_{1}, c_{2}, c_{3}$ are mean impurity concentrations relatively in the $1^{\text {st }}, 2^{\text {nd }}$ and $3^{\text {rd }}$ reservoirs, defined in $\mathrm{kg} / \mathrm{m}^{3}$; $s, s_{1}, s_{2}, s_{3}$ are water flows, defined in $\mathrm{m}^{3} / \mathrm{sec} ; V_{1}, V_{2}, V_{3}$ are water volumes, defined in $\mathrm{m}^{3} ; I$ is discharges intensity, defined in $\mathrm{kg} / \mathrm{sec}$; $t$ is the time, defined in sec. The following conditions conforming to a total flow balance are accepted for the system.

$$
s 1+s 2=s ; s 2=s 3 ; s 1+s 3=s,
$$

Let us consider the impurity concentration dynamics in each of the water reservoirs in the case of discharge impact with constant intensity $I(t)=I=$ constduring some period $T$. In this case, it is possible to present an approximation function of the impact discharge in the form of a rectangle as shown in Figure 3.

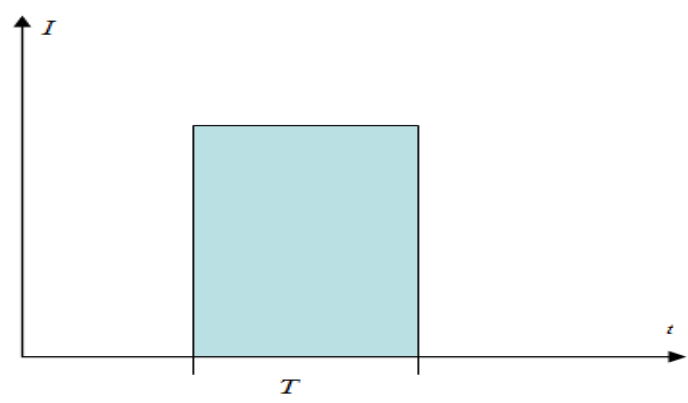

Figure 3. Scheme of the peak discharge

The impurities concentrations in the water reservoirs are $c_{1}(0)=c_{1(0)}, c_{2}(0)=c_{2(0)}, c_{3}(0)=c_{3(0)}$ - in the case of the initial discharge moment.

\subsection{A case of the filtration availability through the soil}

It is possible to transform a dynamic model (1) of pollution of reservoirs with impurities that have a stable composition and take into account the filtration process:

$$
\left\{\begin{array}{c}
V_{1} \frac{d c_{1}}{d t}=I(t)-s_{0} * c_{1}=I(t)-\left(s_{1}+s_{2}\right) * c_{1} \\
V_{2} \frac{d c_{2}}{d t}=\varphi_{1} * s_{1} * c_{1}-\varphi_{1} * s_{1} * c_{2} \\
V_{3} \frac{d c_{3}}{d t}=\varphi_{2} * s_{2} * c_{1}+\varphi_{3} * \varphi_{1} * s_{1} * c_{2}-\left(\varphi_{1} * \varphi_{3} * s_{1}+s_{1} s_{1} c_{1}+\varphi_{2} s_{2}\right) * c_{3}(I I I)
\end{array}\right.
$$

where $c_{1}, c_{2}, c_{3}$ can be considered as the impurity concentrations relatively in the $1^{\text {st }}, 2^{\text {nd }}$ and $3^{\text {rd }}$ reservoirs, $\mathrm{kg} / \mathrm{m}^{3} ; s_{0}, s_{1}, s_{2}, s_{k}$ can be considered as the water flows, defined in $\mathrm{m}^{3} / \mathrm{sec} ; V_{1}, V_{2}, V_{3}$ are water volumes, defined in $\mathrm{m}^{3} ; I$ is discharges intensity, defined in $\mathrm{kg} / \mathrm{sec} ; t$ is the time, defined in sec; $\phi_{1}, \phi_{2}, \phi_{3}$ are the coefficients of filtration. Conditions (4) were accepted for the system (3).

$$
s_{1}+s_{2}=s_{0} ; s_{k}=\phi_{1} * \phi_{3} * s_{1}+\phi_{2} * s_{2}
$$
respectively:

In the initial discharge moment, the impurities concentrations in the water reservoirs were,

$$
c_{1}(0)=c_{1(0)}, c_{2}(0)=c_{2(0)}, c_{3}(0)=c_{3(0)}
$$

in the article [23], it was was considered a solution of the system (3). The next section gives the results of numerical experiments for both cases.

\section{NUMERICAL EXPERIMENT RESULTS}

Figures 4 and 5 show graphs that fix the temporal dynamics of the concentration of impurities during and after the discharge, neglecting water filtration in the soil. It can be seen here that the average 
values of the concentration of impurities in individual tanks during the discharge process begin to increase, and then, having reached certain values, they reach a plateau. Consequently, a constant total concentration reaches equilibrium in each of the reservoirs, provided that the discharge has a constant intensity for a long time. At the same time, the dynamics of concentrations in individual water bodies can have significant differences during a short discharge duration. Further, we can notice that after the start of the discharge, the impurity concentration in the first reservoir increases much faster compared to the same concentrations $c_{1}(0)=0, c_{2}(0)=0, c_{3}(0)=0$ in the remaining reservoirs. For example, the following time intervals were considered: $4,65 \cdot 10^{5} \mathrm{sec}, 4 \cdot 10^{5} \mathrm{sec}$ and $1 \cdot 10^{5} \mathrm{sec}$. Consequently, the experimental data at $\mathrm{T}=4,65 \cdot 10^{5}$ impurity concentrations in water bodies when discharged into all three reservoirs were $99,991 \mathrm{~kg} / \mathrm{m}^{3}, 99,653$ $\mathrm{kg} / \mathrm{m}^{3}, 99,413 \mathrm{~kg} / \mathrm{m}^{3}$, respectively.

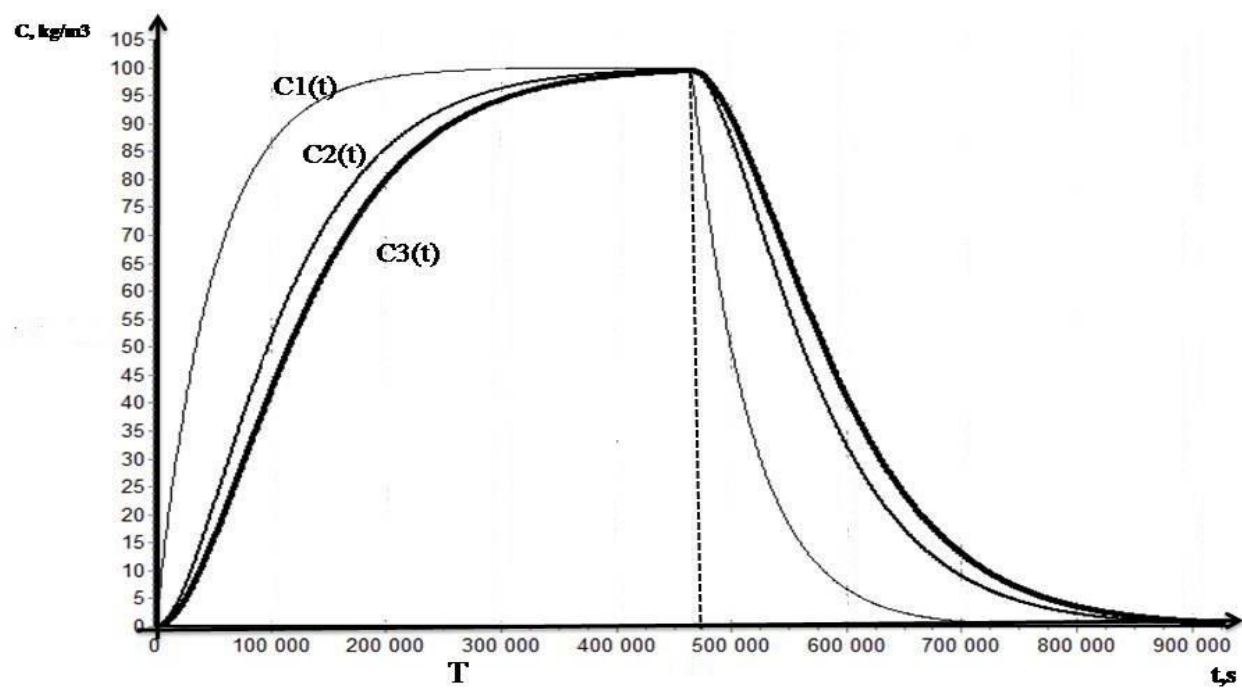

Figure 4. Graphs of changes in time of impurity concentration in 3 reservoirs, occurring during and after discharge at $\mathrm{T}=4,65 \cdot 10^{5} \mathrm{sec}$

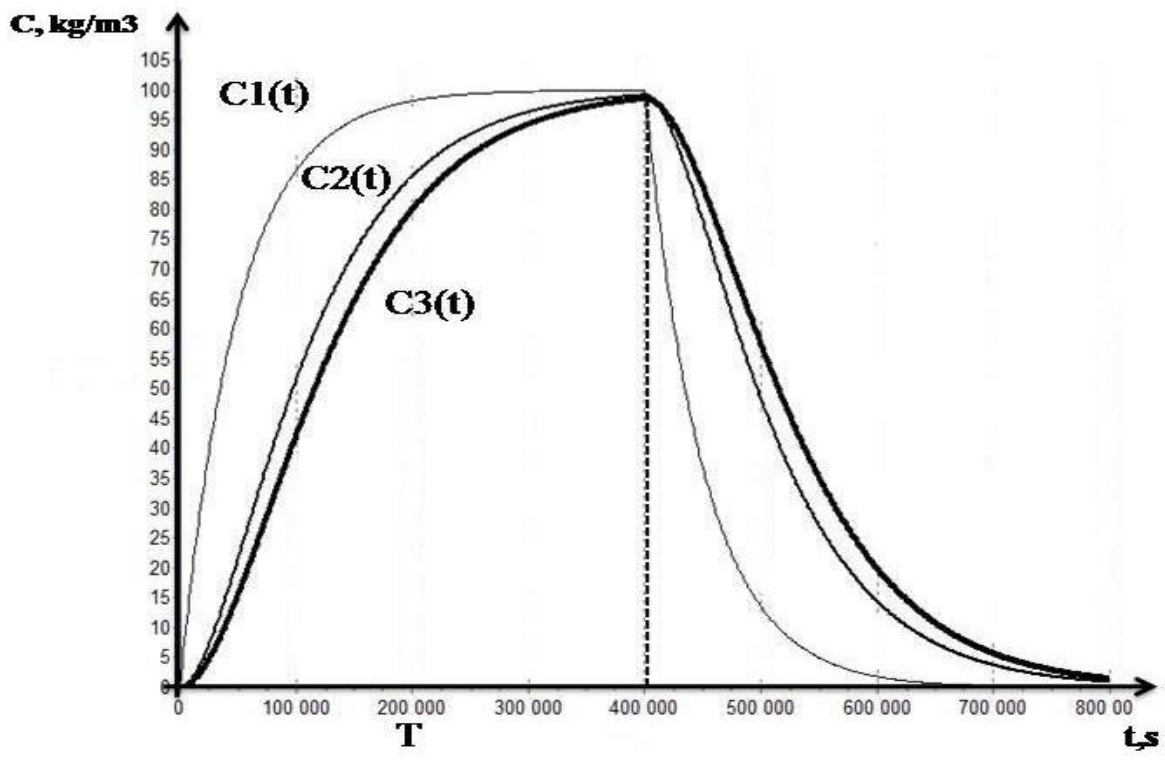

Figure 5. Graphs of changes in time of impurity concentration in 3 reservoirs, occurring during and after discharge at $\mathrm{T}=4 \cdot 10^{5} \mathrm{sec}$

At the same time, impurity concentration curves $\left(C_{1}, C_{2}, C_{3}\right)$ were calculated for a certain set of filtration coefficients in all reservoirs. The following are examples of filtration coefficients: 
1. $\varphi_{1}=0,2, \varphi_{2}=0,6, \quad \varphi_{3}=0,8 ; \quad$ 2. $\varphi_{1}=1, \varphi_{2}=1, \varphi_{3}=1 ; \quad 3 . \varphi_{1}=0,2$,

$$
\begin{aligned}
& \varphi_{2}=0,2, \varphi_{3}=0,2 ; 4 \text {. } \varphi_{1}=0,8, \\
& \varphi_{2}=0,8, \varphi_{3}=0,8 ; \quad \text { 5. } \varphi_{1}=0,2, \varphi_{2}=0,8, \varphi_{3}=0,6 ; 6 . \varphi_{1}=0,8, \varphi_{2}=0,6, \varphi_{3}=0,2 .
\end{aligned}
$$

Discharge duration options from 200000 to $800000 \mathrm{sec}$ were considered. Below you can see some results of the numerical experiment. For example, Figures 6 and 7 show graphs of the time dependence of the concentration in the 1-st reservoir at $\phi_{1}=0,2, \phi_{2}=0,8, \varphi_{3}=0,6$ for various $\mathrm{T}_{1}, \mathrm{~T}_{2}, \mathrm{~T}_{3}, \mathrm{~T}_{4}$.

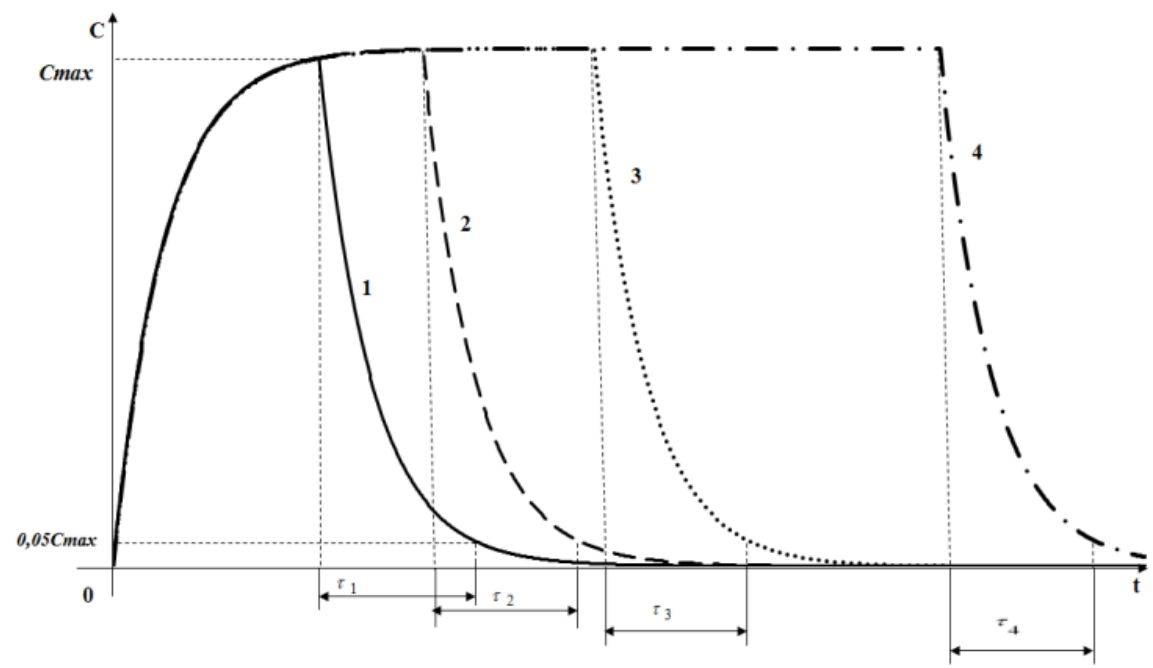

Figure 6. " $C-t$ " curves of the impurity dynamics in the first reservoir in various discharge durations $\mathrm{T}_{1}, \mathrm{~T}_{2}$, $\mathrm{T}_{3}, \mathrm{~T}_{4}\left(\phi_{1}=0,2, \phi_{2}=0,8, \phi_{3}=\varphi_{3}=0,6\right)$

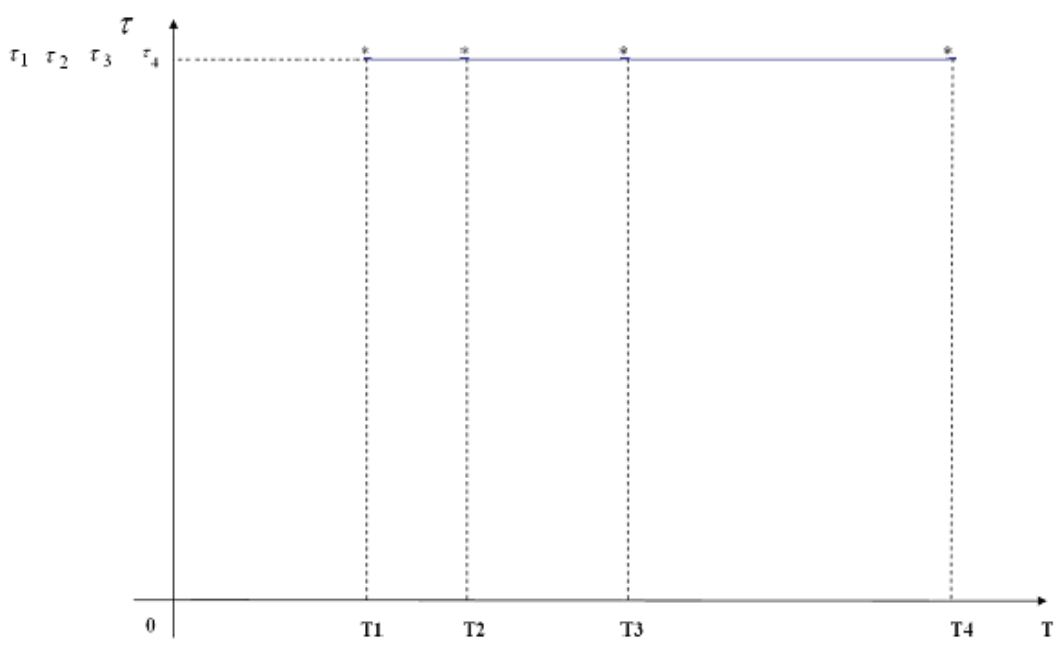

Figure 7. Graph of the time dependence of relaxation on the duration of the discharge in the first reservoir at $\phi_{1}=0,2, \phi_{2}=\phi_{2}=0,8, \phi_{3}=\varphi_{3}=0,6$

Next, relaxation periods $\tau$ were determined for the duration of each discharge, characterized by the fact that the concentration during this period decreases sharply after the completion of the discharge from $C_{\max }$ to $0.05 C_{\max }$. The experimental data obtained in the course of numerical experiments showed that the relaxation periods in the 1-st reservoir are similar and have a value of about $150000 \mathrm{sec}$, taking into account a certain discharge amplitude. With an increase in the duration of the discharge, the relaxation period increased 
in the second reservoir, which was considered with similar filtration coefficients and discharge duration values calculated in the first reservoir. Summarizing the data obtained from the graphs, we can say that the dynamics of the flow duration in the first reservoir does not depend on filtration, just as the relaxation phases in any filtration installations do not have any dependence on the flow duration in the first two reservoirs. But at the same time, the third reservoir has a relaxation phase, which directly depends on the given filtration coefficients, as well as on the duration of the discharge.

\section{APPROVAL OF SOFTWARE SYSTEM FOR ANALYSIS OF TOXIC IMPURITIES CONCENTRATIONS IN THE SYSTEM OF COMMUNICATING WATER RESERVOIRS}

Modern research-practical environmental problems put qualitatively new requirements on the computer processing of information. Similar problems are characterized by labor-intensive processing of input and output information, in this connection, the role of computational simulation and experiment increases [24], [25]. This section considers questions of creation and approval of software systems for analysis of changes in the impurity concentration in the systems of communicating water reservoirs. Earlier we considered systems consisting of three running reservoirs with the pollution source of specified intensity on the bank of one of the reservoirs [25]. Mathematical models that describe the dynamic pollution of reservoirs with various stable impurities, both with and without filtration in the soil, are described in these works. Decisions, worked out in the course of the research objective, were directly used during development of the software system in DELPHI environment. The software system is assigned for automation of processing and computation using specified initial data. The program has means of dialogue interaction with a user at fulfilment of special actions, and convenient interface. A project, implemented in DELPHI environment, consists of eight interrelated forms. After the program start, a window with information about software system appears as shown in Figure 8. This window is the main one, and it is used for transit to other windows of our application. After choice of one of possible options in the list, the required window of the program appears. Figures 9 and 10 show windows of programs for two studied cases.

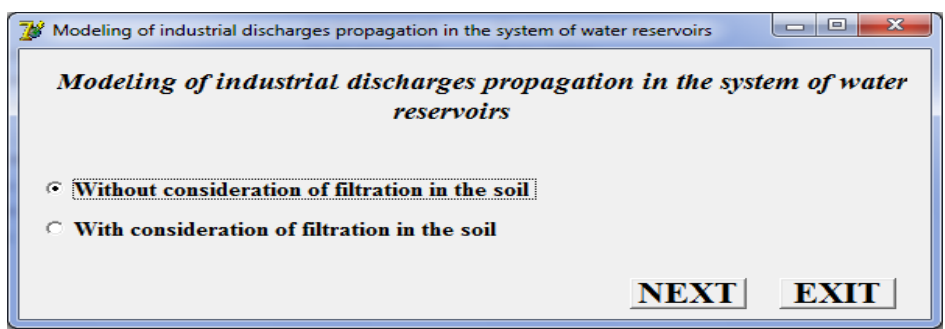

Figure 8. Basic form

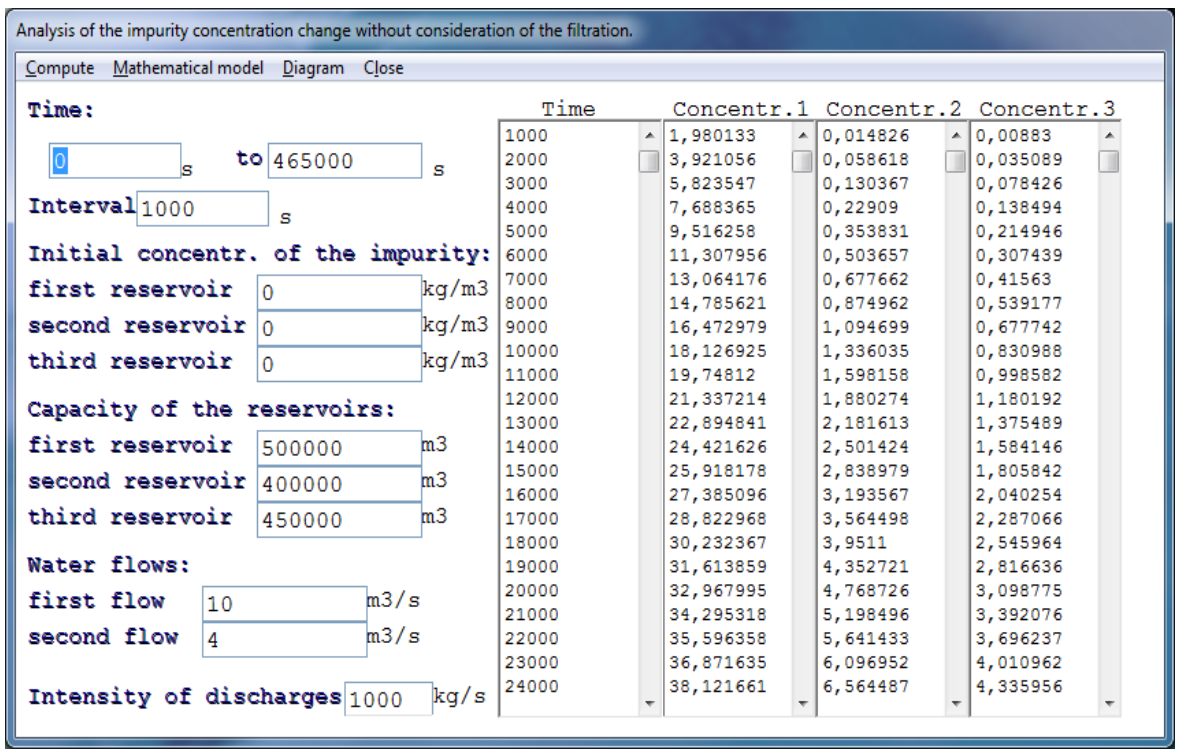

Figure 9. Window for analysis of the impurity concentration change without the filtration 


\begin{tabular}{|c|c|c|c|c|c|c|c|c|c|c|c|c|}
\hline \multicolumn{13}{|c|}{ Analysis of the impurity concentration change with cons } \\
\hline \multicolumn{13}{|c|}{ Compute Mathematical model Diagram Close } \\
\hline \multicolumn{13}{|c|}{ Time: } \\
\hline 0 & to & 465000 & & $s$ & 1000 & A & 1,980133 & A & 0,002977 & A & 0,005287 & . \\
\hline \multirow{2}{*}{\multicolumn{5}{|c|}{ Interval 1000}} & 2000 & ( & 3,921056 & & 0,011818 & & 0,020964 & \\
\hline & & & & & 3000 & & 5,823547 & & 0,026388 & & 0,046759 & \\
\hline \multirow{2}{*}{\multicolumn{5}{|c|}{$\begin{array}{l}\text { Initial concentr. } \\
\text { first reservoir }\end{array}$}} & 4000 & & 7,688365 & & 0,046558 & & 0,082408 & \\
\hline & & 0 & & $\mathrm{~kg} / \mathrm{m} 3$ & $\begin{array}{l}5000 \\
6000\end{array}$ & & 9,516258 & & 0,072197 & & 0,127651 & \\
\hline \multirow{3}{*}{\multicolumn{2}{|c|}{$\begin{array}{l}\text { second reservoir } \\
\text { third reservoir }\end{array}$}} & $\frac{0}{0}$ & & $\mathrm{~kg} / \mathrm{m}^{3}$ & $\begin{array}{l}6000 \\
7000\end{array}$ & & 11,307956 & & 0,10318 & & 0,182233 & \\
\hline & & 0 & & $\mathrm{~kg} / \mathrm{m} 3$ & 8000 & & 13,064176 & & 0,139385 & & 0,245906 & \\
\hline & & 0 & & $\mathrm{~kg} / \mathrm{m} 3$ & 9000 & & 14,785621 & & 0,180689 & & 0,318427 & \\
\hline \multirow{2}{*}{\multicolumn{5}{|c|}{ Capacity of the reservoirs: }} & 10000 & & $\begin{array}{l}16,472979 \\
18,126925\end{array}$ & & 0,226975 & & 0,399557 & \\
\hline & & & & & 11000 & & $\begin{array}{l}18,126925 \\
19,74812\end{array}$ & & $\begin{array}{l}0,278127 \\
0,334031\end{array}$ & & 0,489063 & \\
\hline \multirow{5}{*}{\multicolumn{2}{|c|}{$\begin{array}{l}\text { first reservoir } \\
\text { second reservoir } \\
\text { third reservoir } \\
\text { Water flows: }\end{array}$}} & 500000 & & $\mathrm{~m} 3$ & $\begin{array}{l}12000 \\
13000\end{array}$ & & 21,337214 & & $\begin{array}{l}0,334031 \\
0,394575\end{array}$ & & $\begin{array}{l}0,586719 \\
0,6923\end{array}$ & \\
\hline & & 400000 & & & $\begin{array}{l}13000 \\
14000\end{array}$ & & 22,894841 & & 0,45965 & & 0,805589 & \\
\hline & & 450000 & & & 15000 & & 24,421626 & & 0,529151 & & 0,926372 & \\
\hline & & 450000 & & m3 & 16000 & & 25,918178 & & 0,602971 & & 1,054441 & \\
\hline & & & & & 17000 & & 27,385096 & & 0,681008 & & 1,189592 & \\
\hline \multirow{3}{*}{$\begin{array}{l}\text { first flow } \\
\text { second flow }\end{array}$} & 6 & & & & 18000 & & 28,822968 & & 0,763162 & & 1,331624 & \\
\hline & ${ }^{6}$ & & $\mathrm{~m} 3 / \mathrm{s}$ & & 19000 & & 30,232367 & & 0,849334 & & 1,480343 & \\
\hline & 4 & & $\mathrm{~m} 3 / \mathrm{s}$ & & 20000 & & 31,613859 & & 0,939428 & & 1,635557 & \\
\hline \multirow{2}{*}{\multicolumn{4}{|c|}{ Intensity of discharges 1000}} & $k \alpha / a$ & $\begin{array}{l}21000 \\
22000\end{array}$ & & 32,967995 & & 1,03335 & & 1,79708 & \\
\hline & & & & $\mathrm{kg} / \mathrm{s}$ & $\begin{array}{l}22000 \\
23000\end{array}$ & & 34,295318 & & 1,131006 & & 1,964728 & \\
\hline \multirow{2}{*}{\multicolumn{4}{|c|}{ Filtration coefficients: }} & & 24000 & & 35,596358 & & 1,232306 & & 2,138323 & \\
\hline & & & & & 25000 & & $\begin{array}{l}36,871635 \\
38,\end{array}$ & & $\begin{array}{l}1,337161 \\
1,445484\end{array}$ & & 2,317691 & \\
\hline \multirow{3}{*}{\multicolumn{2}{|c|}{$\begin{array}{l}\text { first reservoir } \\
\text { second reservoir } \\
\text { third reservoir }\end{array}$}} & 0,2 & & & 26000 & & $\begin{array}{l}38,121661 \\
39,346934\end{array}$ & & $\begin{array}{l}1,475404 \\
1,55719\end{array}$ & & $\begin{array}{l}2,502659 \\
2,693061\end{array}$ & \\
\hline & & 0,6 & & & $\begin{array}{l}28000 \\
28000\end{array}$ & & 40,547945 & & 1,672195 & & 2,888733 & \\
\hline & & 0,8 & & & 29000 & & $\begin{array}{l}41,725175 \\
42,879094\end{array}$ & & 1,790417 & & $\begin{array}{l}3,089516 \\
3,295253\end{array}$ & \\
\hline
\end{tabular}

Figure 10. Window for analysis of the impurity concentration change with filtration

Each of the above windows contains 4 buttons: "compute", "mathematical model", "diagram", and "close". For operation of the program, in the left field of the windows, it is necessary to set data, defining the duration of the discharge, concentration of pollutants in all water reservoirs in the initial moment of time, capacity of the reservoirs, rate of water by flows, and intensity of the discharge, moreover, values of the filtration coefficients are additionally put in for the window of Figure 8. The output data of the program are mean concentrations of the impurity in each of the reservoirs in the specified time, presented in the right field of Figures 7 and 8, and also diagrams of temporal dynamic concentration of the impurity in the water reservoirs both during and after the discharge. Figures 11 and 12 show diagrams of temporal dynamic concentration of the impurity in three water reservoirs during and after the discharge at $\mathrm{T}=4,65 \cdot 10^{5}$ sec with consideration and without consideration of the filtration.

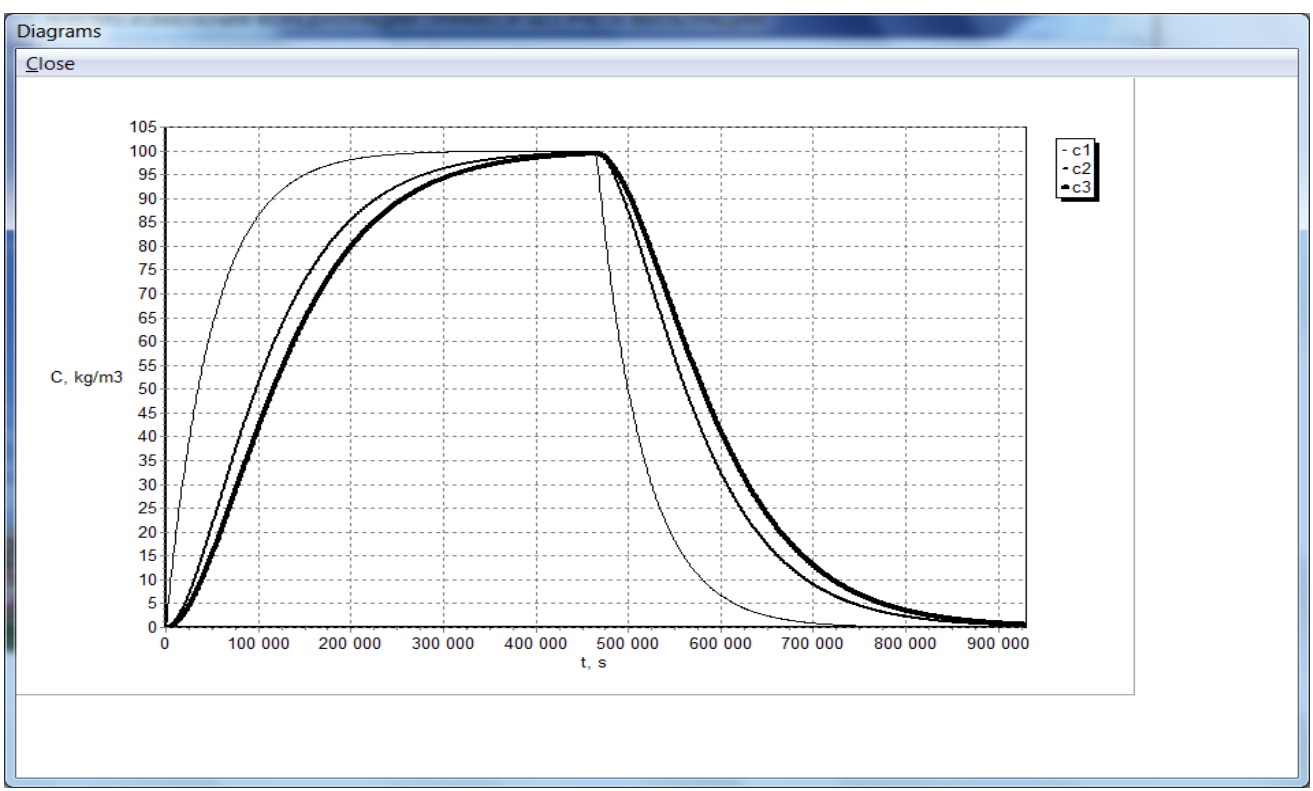

Figure 11. Diagram of temporal dynamic concentration of the impurity in three water reservoirs during and after the discharge at $\mathrm{T}=4,65 \cdot 10^{5} \mathrm{sec}$ without consideration of the filtration 


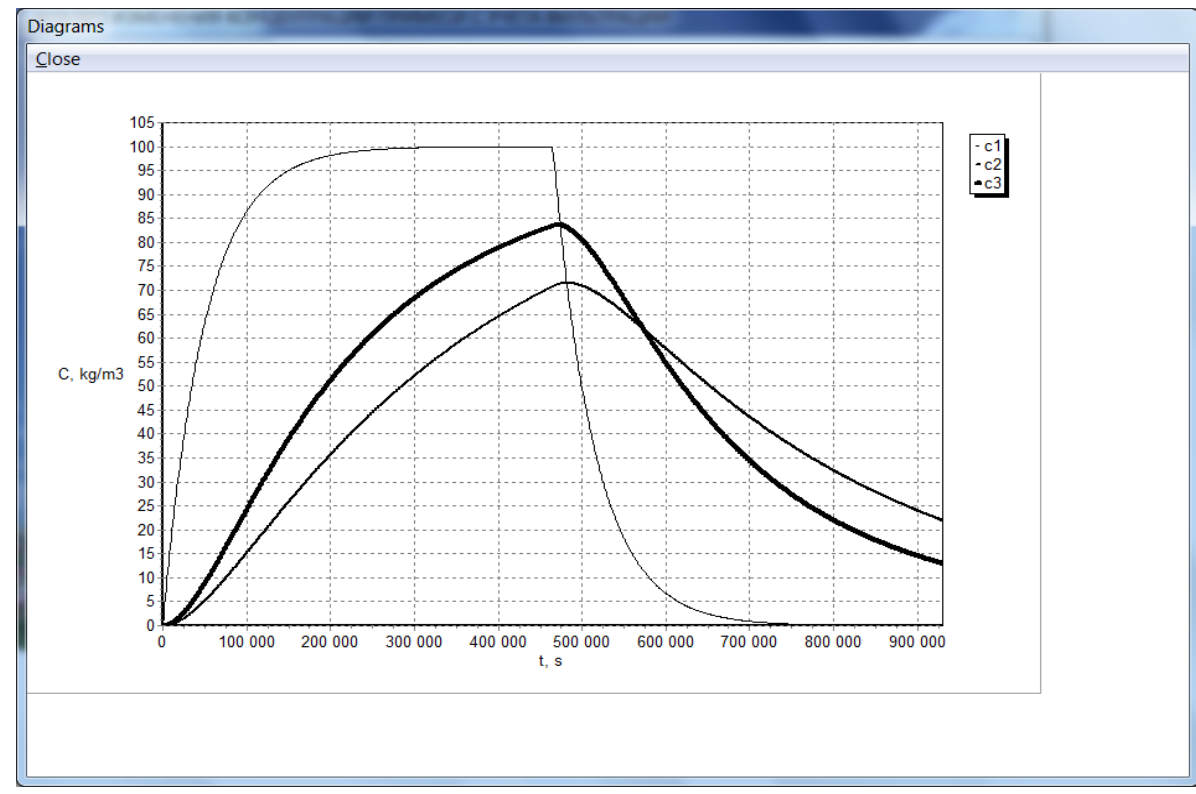

Figure 12. Diagram of temporal dynamic concentration of the impurity in three water reservoirs during and after the discharge at $\mathrm{T}=4,65 \cdot 10^{5} \mathrm{sec}$ with consideration of the filtration

Obtained results allow easily to determine the values of the impurity concentrations in each of the reservoirs at any moment during and after the discharge. "Mathematical model" button in the windows (Figures 9 and 10) gives a graphic theoretical presentation of the studied research objects. For convenient review of the obtained results, there are auxiliary tools in the program. Computing results are automatically stored in files of "Notes" in the standard program. The graphic part of the program is implemented by Diagram component (TChart). This strong and high-powered component was developed by David Berneda, it allows construct complex diagrams on the basis of different data. The operability of the program is confirmed by the fact that the experiments were carried out with given initial conditions obtained from analytical solutions, which, in turn, were correlated with the numerical data of the calculated results using application programs such as Mathcad Prime 2.0, and MATLAB. Analysis of the software system allows to make the following conclusions:

- The program allows operating by large bodies of input data;

- Results, obtained during operation with the program, differ by high accuracy;

- The software system has sufficient clear visualization, as it was performed in the environment of visual programming DELPHI;

- $\quad$ The program has high performance and operability;

- lso, the program can be used in the process of modeling tasks that solve the problems of the distribution of industrial discharges in the system of communicating reservoirs.

\section{CONCLUSION}

The research analysis allows to conclude that the picture of the propagation of pollutants contained in waste waters entering water systems from production depends on the type of industrial enterprise. Accordingly, when studying the interaction of impurities in the water environment, it is necessary to take into account their qualitative composition. The simplified model for analyzing the relaxation propagation of the impurity in the system of communicating water reservoirs has been submitted. Approval of the model was carried out for the systems, which consist of three running reservoirs both with consideration and without consideration of the water filtration in the soil. The system of equations for balance of the water reservoirs pollution by the stable impurity was derived and solved. The temporal dynamic concentration of the impurity in three water reservoirs during and after the discharge, during certain period, in the systems without filtration through the water reservoir bottom was studied. The similar model for dynamic pollution of the systems of communicating reservoirs with consideration of the water filtration in the soil was constructed. The analysis of dynamic concentration of the impurity in the system of communicating reservoirs with consideration of the impurity diffusion in the reservoirs and filtration in the soil was also carried out. 
Water systems function and develop in time and space under the influence of internal laws. The existing change tendencies in the system parameters remain in the form of a trace over a certain period. With this approach, it becomes possible to identify not only the qualitatively correct tendency of the system, but also to obtain calculated dependencies for a reliable forecast. Relaxation models are highly flexible and adaptable. The numerical experiments at different discharge durations and compositions of the filtration coefficients were carried out to study the pollution relaxation times in the system of water reservoirs. It was revealed that the relaxation time in the first and second reservoirs does not depend on the discharge duration at any filtration compositions, however, this dependence is observed for the third reservoir. The pollution relaxation time dependence in the third reservoir is explained by location of this object in the system of communicating water reservoirs. It was established that the pollution picture to a large extent depends on the scheme of the water flows net. The pollutant particles' propagation in the water environment depends on their size and chemical nature; therefore, relaxation occurs at different rates, being a multi-step process. Various systems are characterized by their own relaxation features due to the nature of the interaction between the particles of the system.

During modeling of the industrial discharge propagation in the system of communicating water reservoirs, the questions of creation and approval of the software system to analyze the impurity concentration change in the system of these water reservoirs were considered. Results obtained during operation with the program can be applied in researches of the industrial discharges propagation modeling in the system of communicating water reservoirs. It is possible to use our models to calculate these effects, while adequately predicting the change in the concentration of an admixture in various systems of connected reservoirs. Also, based on this approach, it is possible to calculate the maximum values of concentrations for forecasting the time, the duration of which is necessary when determining the excess of the maximum permissible concentration after the discharge of impurities into reservoirs.

The results of the calculations led to the fact that there is some time delay in the dependence of concentration on time for the impurity concentration in each of the reservoirs. However, after the discharge is completed, there may be a temporary increase in the concentration of impurities in the event of a delay in a water body remote from the point of direct discharge, even in the case of a small amount of discharge. Observations of temporal changes in pollution in the case of discharge and relaxation confirmed numerical experiments, which showed the adaptability of the developed model. This suggests that this method can be recommended for research, analysis, and forecasting of dynamic environmental pollution in industrial areas. Thus, the use of mathematical methods, models and special software products allows to study the features of a water body and its sources of pollution, carry out extensive monitoring and make a qualitative comparison with indicators of previous years, and assess the functioning and development of the water system in the near future.

\section{ACKNOWLEDGEMENTS}

The authors thank the Republican Research Center on Safety Problems in Chemical and Food Industries for providing the basis for this study, which was carried out and implemented within the framework of the program "Monitoring, Modeling, and Forecasting of Disasters and Technogenic Accidents in Chemical and Food Industries" under the section "Computer and mathematical analysis of data on disasters and technogenic accidents in chemical and food industries of the Republic of Kazakhstan".

\section{REFERENCES}

[1] S. Ebrahimi and M. Khorram, "Variability effect of hydrological regime on river quality pattern and its uncertainties: Case study of Zarjoob River in Iran," Journal of Hydroinformatics, vol. 23, no. 5, pp. 1146-1164, Aug. 2021, doi: 10.2166/hydro.2021.027.

[2] L. Chen et al., "Water environmental capacity calculated based on point and non-point source pollution emission intensity under water quality assurance rates in a tidal river network area," International Journal of Environmental Research and Public Health, vol. 16, no. 3, p. 428, Feb. 2019, doi: 10.3390/ijerph16030428.

[3] X. Ding and P. Fang, "Accident trend prediction of heavy metal pollution in the Heshangshan drinking water source area based on integrating a two-dimensional water quality model and GIS," Sustainability (Switzerland), vol. 11, no. 15, p. 3998, Jul. 2019, doi: 10.3390/su11153998.

[4] H. C. Hsu and W. S. Fan, "Engineering management on modeling of environmental protection," Advanced Materials Research, vol. 734-737, pp. 3352-3355, Aug. 2013, doi: 10.4028/www.scientific.net/AMR.734-737.3352.

[5] Q. A. Dang, M. Ehrhardt, G. L. Tran, and D. Le, "Mathematical Modeling and Numerical Algorithms for Simulation of Oil Pollution," Environmental Modeling and Assessment, vol. 17, no. 3, pp. 275-288, Sep. 2012, doi: 10.1007/s10666-011-9291-1

[6] B. Liu, "Water pollution control system optimisation model and computer solution," International Journal of Modelling, Identification and Control, vol. 16, no. 3, pp. 285-290, 2012, doi: 10.1504/IJMIC.2012.047740.

[7] D. Gordeziani, "Plenary lecture 3: on mathematical models and numerical algorithms for solution of some problems of water pollution," in Proceedings of the 15th WSEAS International Conference on Applied Mathematics, 2010, pp. 14-15, [Online]. Available: http://dl.acm.org/citation.cfm?id=1938992.1938995.

[8] H. Milišić, E. Hadžić, A. Mulaomerović-Šeta, H. Kalajdžisalihović, and N. Lazović, "Mathematical Modeling of Surface Water Quality," in Lecture Notes in Networks and Systems, vol. 60, Springer International Publishing, 2019, pp. 138-156. 
[9] E. A. Nysanov, S. D. Kurakbayeva, Z. R. Umarova, S. B. Botayeva, and Z. A. Makhanova, "Modeling of the selecting optimum cross section of open canals," Applied Mathematics and Information Sciences, vol. 9, no. 2, pp. 615-618, 2015, doi: 10.12785/amis/090209.

[10] A. Mohan, “Algorithm Development for Water Quality Prediction System Along Industrial Outfall River Stretch Using Modeling and Computer Simulation," International Journal of Engineering Science and Technology, vol. 2, no. 11, pp. 6204-6208, 2010.

[11] V. I. Danilov-Danilyan and I. L. Khranovich, "A System of Mathematical Models Underlying Water Use and Disposal Strategies," Water Resources, vol. 45, no. 2, pp. 289-296, Mar. 2018, doi: 10.1134/S0097807818020057.

[12] Z. Qiao, L. Ma, T. Liu, and X. Huang, "An ecological stability-oriented model for the conjunctive allocation of surface water and groundwater in oases in arid inland river basins," Water Science and Technology: Water Supply, vol. 21, no. 1, pp. 368-385, Nov. 2021, doi: 10.2166/ws.2020.305.

[13] X. Qin and L. Zheng, "Mathematical models for analysis of water pollution," Applied Mechanics and Materials, vol. 209-211, pp. 1941-1947, Oct. 2012, doi: 10.4028/www.scientific.net/AMM.209-211.1941.

[14] A. Ziemińska-Stolarska and J. Skrzypski, "Review of mathematical models of water quality," Ecological Chemistry and Engineering S, vol. 19, no. 2, pp. 197-211, Jan. 2012, doi: 10.2478/v10216-011-0015-x.

[15] J. Yazdi and A. Moridi, "Interactive Reservoir-Watershed Modeling Framework for Integrated Water Quality Management," Water Resources Management, vol. 31, no. 7, pp. 2105-2125, Mar. 2017, doi: 10.1007/s11269-017-1627-4.

[16] Y. Fang and Y. Min, "Application of MIKE 11 model in the prediction of water pollution accident in the Three Gorges Reservoir," in Dams and Reservoirs under Changing Challenges - Proceedings of the International Symposium on Dams and Reservoirs under Changing Challenges - 79 Annual Meeting of ICOLD, Swiss Committee on Dams, \{CRC\} Press, 2011, pp. 813-819.

[17] L. Y. Tsai, C. F. Chen, C. H. Fan, and J. Y. Lin, "Using the HSPF and SWMM models in a high pervious watershed and estimating their parameter sensitivity," Water (Switzerland), vol. 9, no. 10, p. 780, Oct. 2017, doi: 10.3390/w9100780.

[18] L. Yuan, T. Sinshaw, and K. J. Forshay, "Review of watershed-scale water quality and nonpoint source pollution models," Geosciences (Switzerland), vol. 10, no. 1, p. 25, Jan. 2020, doi: 10.3390/geosciences 10010025.

[19] B. T. Long, "Inverse algorithm for Streeter-Phelps equation in water pollution control problem," Mathematics and Computers in Simulation, vol. 171, pp. 119-126, May 2020, doi: 10.1016/j.matcom.2019.12.005.

[20] S. Kurakbayeva, A. Kalbayeva, A. Brener, E. Musirepova, and S. Akhmetova, "Mathematical modeling the relaxation impact of water pollutions in the system of reservoirs under the one-time emissions through a broken dam," Chemical Engineering Transactions, vol. 82, pp. 355-360, Oct. 2020, doi: 10.3303/CET2082060.

[21] S. Kurakbayeva, A. Kalbayeva, B. Shakirov, and A. Brener, "Simulation of industrial discharges relaxation impact on water bodies," Proc. of the 1st International Conference on Hydrology and Ecology (HYEC'13), 2013.

[22] D. Kurakbayeva, S. Kurakbayev, and M. Saprygina, "On Modelling the Relaxational Impact of Water Pollutions in System of Flow-through Reservoirs," in Proc. of the 2015 International Conference Water Resources, Hydraulics \& Hydrology (WHH 2015), 2015, pp. 314-317.

[23] J. K. J. and D. B. N. and A. V. Gotovtsev, "Web-oriented quality assessment system for surface waters of river reservoir," Periodico tche quimica, vol. 16, no. 33, pp. 457-471, 2019

[24] Y. M. Yu, "Research on virtual simulation of pollution diffusion in oil pollution accident based on environmental protection concept," Health \& Environmental Research Online (HERO), vol. 30, no. 1, pp. 541-549, 2021.

[25] S. D. Kurakbayeva, Z. R. Umarova, S. B. Botayeva, and G. A. Besbayev, "Modeling and Development of a Software Complex for Calculating Pollution Propagation in a Water Bodies," Applied Mathematics and Information Sciences, vol. 9, no. 4, pp. 1699-1708, 2015, doi: 10.12785/amis/090406.

\section{BIOGRAPHIES OF AUTHORS}

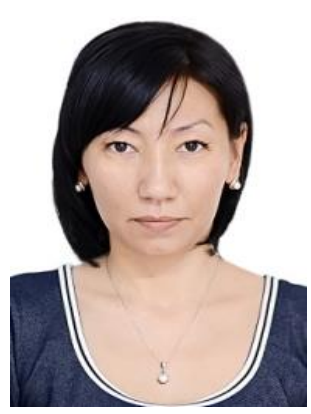

Sevara Dzhumagaliyevna Kurakbayeva (iD) $8 \mathrm{SC}$ ( $\mathrm{p}$ received the candidate of technical science degree in mathematical modeling from Ministry of Education and Science, in 2010. Currently she works as an associated professor of Information Systems and Modeling department at M. Auezov South Kazakhstan University. Her research interests include mathematical modeling, computer simulation, computer science, and computer graphics. She can be contacted at email: sevam@mail.ru.

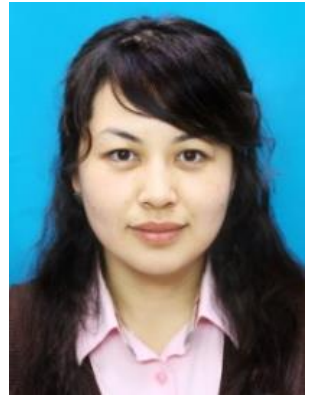

Zhanat Rysbayevna Umarova (iD) $\mathrm{SC}$ P received her $\mathrm{PhD}$ degree in Iformatics, Computer Engineering and Control from Ministry of Education and Science, in 2013. Currently she works as an Associated Professor of Information Systems and Modeling department at M. Auezov South Kazakhstan University. She has supervised and co-supervised more than 20 masters' students. She has authored or coauthored more than 100 publications. Her research interests include Mathematical modeling, Computer simulation, Information security and data protection in information systems, Web-programming, Renewable recourses. She can be contacted at email: Zhanat.umarova@auezov.edu.kz. 


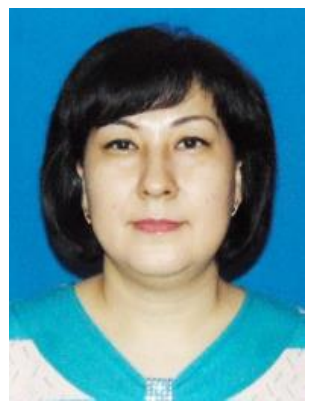

Aizhan Tazhiklhanovna Kalbayeva (iD 80 SC P received the candidate of technical science degree in Processes and apparatuses of chemical technology from Ministry of Education and Science, in 2007. Currently she works as an associated professor of Information Systems and Modeling department at M. Auezov South Kazakhstan University. Her research interests include Mathematical and computer modeling of technological processes, Solution of filtration problems by the method of boundary elements, Programming technology. She can be contacted at email: kalbaeva@mail.ru.

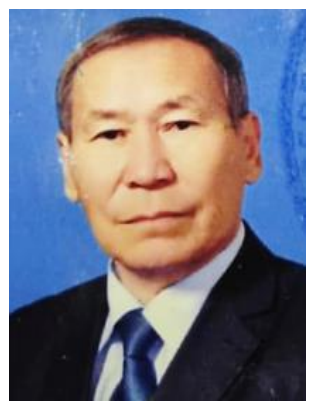

Dzhumagali Salbekovich Kurakbayev (D) 8 SC P received the candidate of Physics and Mathematics science degree in applied mathematics from the Institute of Mechanics and Seismic Resistance of Construction of the Academy of Sciences, Uzbekistan in 1992. Currently he is working as associated professor of Computer science department at $\mathrm{M}$. Auezov South Kazakhstan State University. His research interests include Computer and mathematical modeling, Programming languages and technology, creation software package. He can be contacted at email: kurakbayev@mail.ru.

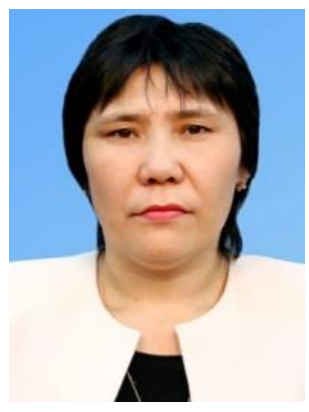

Sabira Tastanovna Akhmetova (D) SC S P received the candidate of Physics and Mathematics science degree in mathematics Ministry of Education and Science, in 2005. Currently she works as the head of the department "Computing systems and software" at M. Auezov South Kazakhstan University. Research interests include Mathematical modeling, Computer simulation, Programming languages and Information security. She can be contacted at email: akhmetova@mail.ru.

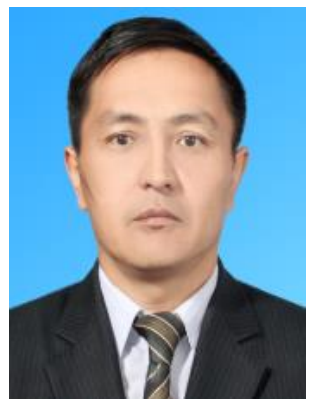

Akhmetbek Akhylbekovich Musabekov (D) 8 SC P received the candidate of technical science degree in systems control from Ministry of Education and Science, in 2010. Currently she works as the head of the department "Automation, telecommunications and control" at M. Auezov South Kazakhstan University. Research interests include Computer simulation, Development and design of automation systems for technological processes. He can be contacted at email: musabekov@mail.ru. 